J. Egypt. Soc. Parasitol. (JESP), 51(1), 2021: 43 - 50

(Online: 2090-2549)

\title{
VALUE OF MCMASTER, MINI-FLOTAC, AND STANDARD TECHNIQUES \\ FOR ASSESSMENT OF THE PREVALENCE OF INTESTINAL HELMINTHS AMONG SCHOOLCHILDREN IN MENOUFIA GOVERNORATE, EGYPT
}

\author{
By \\ OSAMA FATHY SHARAF, SAHAR MAHMOUD SELIM, \\ ISRAA FAHMY EL-HASSANEN AND ASMAA FAHMY IBRAHIM* \\ Department of Clinical and Molecular Parasitology, National Liver Institute (NLI), \\ Menoufia University, Shebin El Kom, Menoufia, Egypt \\ ( ${ }^{*}$ Correspondence: dr_asmaafahmy@yahoo.com) \\ Mobile No.: 01124836909, ORCID ID: 0000-0002-1180-1845

\section{Abstract}

Intestinal helminthiasis affects schoolchildren causing diseases. In this study, five copromicroscopic methods ( 3 traditional and 2 recent; Formaline-ether concentration method (FECM), Kato-Katz, direct smear, McMaster and mini-FLOTAC with two flotation solutions $\mathrm{NaCl} \&$ $\mathrm{ZnSO} 4$ respectively) in addition to scotch adhesive tape method were used to detect helminthic infection in children. Hemoglobin percent and anthropometric measurements were also assessed. Out of 400 school children, 82 (20.5\%) were infected; 75 single \& 7 mixed infections. Enterobius vermicularis was the commonest one $(11 \%)$ followed by Hymenolepis nana $(9.75 \%)$ and the least one was Schistosoma mansoni (1.5\%). The most sensitive method was mini-FLOTAC $\mathrm{ZnSO}_{4}$ while the least one was direct smear, but without a significant difference. Scotch adhesive tape method had the best efficacy for $E$. vermicularis diagnosis. No significant difference was found for egg per gram (EPG) values of the counting techniques. $H$. nana was associated with anemia and underweight. Rural residence, unwashed fruits, and vegetables, unwashed hands before eating and after defecation were the risk factors. Sharing underwear and water canal contact were specifically associated with $E$. vermicularis and $S$. mansoni respectively. The better diagnostic performance were mini-FLOTAC and McMaster methods.

Keywords: Mini-FLOTAC, McMaster, Kato-Katz, FECM, Helminthes, Schoolchildren, Anemia.

\section{Introduction}

Intestinal parasites are among the commonest infections worldwide and cause health problems, particularly in children as anemia and adverse effects on their physical and cognitive growth (Bayoumy et al, 2018). Various risk factors were identified, including low health literacy, poor hygiene, intake of unwashed vegetables and fruit as well as water impurity (Hegazy et al, 2014).

Microscopic stool analysis is the primary tool to detect the intestinal parasites. Direct smear is the simplest and easiest procedure, but with low sensitivity (Abd El-Gaffar et al, 2018). Kato-Katz system, which is simple and low-cost, was recommended for laboratory and epideniological studies. But, its main drawback was the suboptimal vulnerability and misdiagnose of some helminthic eggs due to glycerol clearance effect (Lim et $a l, 2018)$. Formalin-ether concentration me- thod (FECM) needed well-equiped lab. and was time-consuming (Kurt et al, 2012).

The McMaster technique proved to be simple, especially one in less-equipped and lab. technician, but with doubted efficiency in diangosing helminthic eggs (Levecke et $a l, 2011)$. Mini-FLOTAC is a simple, highly sensitive, and quantitative process with the advantage of using fresh or fixed samples (Barda et al, 2014).

The present study aimed to investigate prevalence and risk factors of intestinal helminthiasis among primary schoolchildren in Menoufia Governorate (Nile Delta, Egypt), to determine the helmi-nthiasis effect on children nutritional status, also to compare miniFLOTAC and McMaster techniques with the ordinary stool exmination method.

\section{Subjects and Methods}

Study design and population: Cross-sectional study was achieved on 400 school child- 
ren (6-12 years old) attending primary schools, during the period from February to May 2019. Children were selected using a multistage random sampling method. One city \& one village were chosen from four Governorate districts. The first one was Ashmoon City \& Kafr El-Sayed Village, the second was Berket El Sab City \& Shentena El-Hagar Village, the third was El-Sadat City \& Kafr Dawood Village and the fourth was ElShohada City \& Zawyet El-Bokaly Village.

Ethical consideration: This study was approved by the Committee of Research and Ethics, National Liver Institute, Menoufia University, achieved after endorsement from the MoH\&P with written consent from children's guardians. A standardized questionnaire was used to assemble demographic data and information on possible risk factors.

Stools collection and examination: A sufficient portion of early morning feces was obtained from each child in a labeled, clean, leak-proof, and wide-mouth disposable container. Cellophane tape was sticked perianal and then adhered to a glass slide to detect $E$. vermicularis. Collected samples were tested microscopically by using 1 - direct smear, a small portion of collected stools was put on a slide with a drop of saline (WHO, 1994). 2- Kato Katz, feces were pressed through a mesh screen to discard large elements and part of sieved sample was transferred to slide hole template, which was discarded after hole filling, remained sample (50mg) was covered with a piece of cellophane soaked in glycerol malachite green, and then number of egg per gram (EPG) feces was calculated by multiplying the recovered eggs number by 24 (Katz et al, 1972). 3- FECM, used for more effectiveness of centrifugal sedimentation to recover and concentrate helminths eggs from feces (WHO, 1991). 4- McMaster method, $2 \mathrm{gm}$ of feces were filtrated and homogenized with $30 \mathrm{ml}$ of saturated saline solution, then $1 \mathrm{ml}$ of suspension was added to each chamber and left for $3 \mathrm{~min}$. to float, eggs counted and multiplied by 50 to calculate EPG (Barda et al, 2014a). 5- Mini-FLOT
AC, 2 flotation solutions were used; FS2 saturated sodium chloride with 1.20 specific gravity and FS7, zinc sulfate with $1.35 \mathrm{spec}-$ ific gravity. $2 \mathrm{gm}$ of stool were added to $2 \mathrm{ml}$ formalin (5\%), homogenized, filtered, and added to either $36 \mathrm{ml} \mathrm{FS2}$ or $46 \mathrm{ml} \mathrm{FS7.} \mathrm{Aft-}$ er $10 \mathrm{~min}$, eggs on reading discs were microscopically examined 10x \& $40 \mathrm{x}$, EPG recorded as eggs/gm feces (Barda et al, 2014).

Anthropometric measurements: Bodyweight and height were measured using a scale to the nearest $0.1 \mathrm{~kg} \& 0.1 \mathrm{~cm}$ respectively (Gibson, 2005). Differences from the median in standard deviation units were considered as values. Children classification as stunted, and underweight if height $\&$ weight for age were $<2$ standard deviation below WHO median for age and sex (Onis et al, 2007).

Hemoglobin levels: $\mathrm{Hb}$ was measured by DiaSpect $^{\mathrm{Tm}}$ Hemoglobin Analyzer (EKF Diagnostics, UK) that gave instant results from a finger prick. Children were categorized as anemic if $\mathrm{Hb}$ was $<11.5 \mathrm{~g} / \mathrm{dl}$ (WHO, 2001).

Statistical analysis: Data were collected \& computerized using SPSS (Statistical Package for Social Science) program for statistical analysis (version 20; Inc., Chicago. IL).

\section{Results}

Out of 400 children aged 6-12 years, 82 (20.5\%) were infected; $75(18.75 \%)$ with one parasite and $7(1.75 \%)$ with mixed parasites. E. vermicularis was the commonest parasite (11\%) followed by $H$. nana $(9.75 \%)$ while $S$. mansoni was the least one $(1.5 \%)$.

Sociodemographic data showed that younger age group ( $\leq 8$ years) was significantly associated with parasitic infection, but, all $S$. mansoni cases were among older age group. Males were infected more than females, but without a significant difference. Children living in rural areas were significantly more infected than in urban areas. There was a significant difference in helminthic infection distribution, as Ashmoon showed the highest rate followed by El-Shohada, Berket El Sab, and El-Sadat was the lowest.

The habit of non-washing hands before eating and after defecation, eating outdoors, 
sharing underwear, water canal contact, and consumption of unwashed vegetables and fruits were significantly associated with helminthic infection. Difference between infected and non-infected children as to anemia and underweight was significant, but for stunted children, was not significant.

All the copromicroscopic data were considered as the golden standard diagnosis. The mini-FLOTAC ZnSO4 was highly sensitive follo-wed by mini-FLOTAC NaCl, McMaster, FECM, and Kato-Katz, but the least sensitive one was the direct smear. The negative predictive values of the different methods followed the same order. The Scotch adhe- sive tape method proved to be the best for $E$. vermicularis diagnosis compared to the used copromicroscopic method (44 vs 30 cases respectively).

The ROC curve showed that all used methods had significant AUC compared to combined results (Gr. 1). Regarding the number of eggs per gram of stool, mini-FLOTAC FS2 gave the highest EPG for E. vermicularis and $H$. nana, followed by miniFLOTAC FS7, Mc-Master, and Kato-Katz. In $S$. mansoni, mini-FLOTAC FS7 gave the highest EPG followed by Kato-Katz (Gr. 2).

Details were given in tables $(1,2,3,4$ \& 5) and graphs (1\&2)

Table 1: Intestinal helminths among schoolchildren:

\begin{tabular}{|l|c|}
\hline Helminths recovered & Children number (\%) \\
\hline Single infection & $38(9.5 \%)$ \\
\hline E. vermicularis $*$ & $33(8.25 \%)$ \\
\hline H. nana & $4(1 \%)$ \\
\hline S. mansoni \\
\hline Mixed infection & $5(1.25 \%)$ \\
\hline E. vermicularis + H. nana & $1(0.25 \%)$ \\
\hline E. vermicularis $*$ S. mansoni & $1(0.25 \%)$ \\
\hline H. nana + S. mansoni & . \\
*: E. vermicularis detected by scotch adhesive tape method
\end{tabular}

Table 2: Prevalence of helminthic infections in correlation with sociodemographic data (age, sex, and residence):

\begin{tabular}{|c|c|c|c|c|c|}
\hline \multicolumn{2}{|l|}{ Variable } & $\begin{array}{l}\text { Total examined } \\
(\mathrm{N}=400)\end{array}$ & $\begin{array}{c}\text { Positive cases } \\
\text { (No. }=82 \text { ) }\end{array}$ & $\chi^{2}$ test & P-value \\
\hline \multirow[t]{2}{*}{ Age } & $\leq 8$ years & $218(54.5 \%)$ & $58(70.8 \%)$ & \multirow[t]{2}{*}{10.96} & \multirow[t]{2}{*}{$<0.001 * * *$} \\
\hline & $>8$ years & $182(45.5 \%)$ & $24(29.2 \%)$ & & \\
\hline \multirow[t]{2}{*}{ Sex } & Male & $185(46.3 \%)$ & $44(53.7 \%)$ & \multirow[t]{2}{*}{2.28} & \multirow[t]{2}{*}{0.131} \\
\hline & Female & $215(53.7 \%)$ & $38(46.3 \%)$ & & \\
\hline \multirow[t]{2}{*}{ Residence } & Rural & $200(50 \%)$ & $57(69.5 \%)$ & \multirow[t]{2}{*}{15.71} & \multirow[t]{2}{*}{$<0.001 * * *$} \\
\hline & Urban & $200(50 \%)$ & $25(30.5 \%)$ & & \\
\hline \multirow[t]{4}{*}{ Distribution } & Ashmoon & $100(25 \%)$ & $33(40.2 \%)$ & \multirow[t]{4}{*}{17.36} & \multirow[t]{4}{*}{$<0.001 * * *$} \\
\hline & Berket El Sab & $100(25 \%)$ & $15(18.3 \%)$ & & \\
\hline & El-Sadat & $100(25 \%)$ & $11(13.4 \%)$ & & \\
\hline & El-Shohada & $100(25 \%)$ & $23(28.1 \%)$ & & \\
\hline
\end{tabular}

*Significant $(\mathrm{P}<0.05), * *$ Highly significant $(\mathrm{P}<0.01),{ }^{* * *}$ Very highly significant $(\mathrm{P}<0.001)$

Table 3: Potential risk factors for intestinal helminthic infections among school children:

\begin{tabular}{|c|c|c|c|c|c|c|}
\hline \multicolumn{2}{|c|}{ Variable } & $\begin{array}{l}\text { Positive } \\
(\text { No. }=82)\end{array}$ & $\begin{array}{l}\text { Negative } \\
(\text { No. }=164)\end{array}$ & $\chi^{2}$ test & P-value & $\begin{array}{c}\text { Odds Ratio } \\
(95 \% \text { Confidence Interval })\end{array}$ \\
\hline \multirow{2}{*}{$\begin{array}{l}\text { Washing vege- } \\
\text { tables }\end{array}$} & Yes & 53 & 138 & 11.99 & $<0.001^{* *}$ & 0.3443 \\
\hline & No & 29 & 26 & & $*$ & $(0.1858-0.6381)$ \\
\hline \multirow{2}{*}{$\begin{array}{l}\text { Washing hand } \\
\text { before food }\end{array}$} & Yes & 34 & 99 & 7.86 & $0.005 * *$ & 0.4651 \\
\hline & No & 48 & 65 & & & $(0.2712-0.7976)$ \\
\hline \multirow{2}{*}{$\begin{array}{l}\text { Washing hand } \\
\text { after defecation }\end{array}$} & Yes & 36 & 141 & 47.95 & $<0.001 * *$ & 0.1277 \\
\hline & No & 46 & 23 & & $*$ & $(0.0687-0.2373)$ \\
\hline \multirow{2}{*}{$\begin{array}{l}\text { Sharing under- } \\
\text { wear }\end{array}$} & Yes & 15 & 14 & 5.004 & $0.025^{*}$ & 2.3987 \\
\hline & No & 67 & 150 & & & $(1.0960-5.2497)$ \\
\hline \multirow{2}{*}{$\begin{array}{l}\text { Water canal } \\
\text { contact }\end{array}$} & Yes & 6 & 2 & 6.46 & $0.01 *$ & 6.3947 \\
\hline & No & 76 & 162 & & & $(1.2613-32.422)$ \\
\hline \multirow{2}{*}{$\begin{array}{l}\text { Eating food } \\
\text { outdoors }\end{array}$} & Yes & 23 & 19 & 10.47 & $0.0012 * *$ & 2.9750 \\
\hline & No & 59 & 145 & & & $(1.5089-5.8655)$ \\
\hline
\end{tabular}


Table 4: Effect of helminthic infection on nutritional status and hemoglobin level of infected children:

\begin{tabular}{|c|c|c|c|c|c|c|c|}
\hline \multirow{2}{*}{\multicolumn{2}{|c|}{ Variable }} & \multicolumn{3}{|c|}{ Single infection } & \multirow{2}{*}{$\begin{array}{c}\text { Mixed } \\
\text { infection } \\
(\mathrm{N}=7)\end{array}$} & \multirow{2}{*}{$\begin{array}{l}\text { Negative } \\
(\mathrm{N}=164)\end{array}$} & \multirow[b]{2}{*}{$\mathrm{P}$ value } \\
\hline & & $\begin{array}{c}\text { E. vermicularis } \\
(\mathrm{N}=38)\end{array}$ & $\begin{array}{l}\text { H. nana } \\
(\mathrm{N}=33)\end{array}$ & $\begin{array}{l}\text { S. mansoni } \\
(\mathrm{N}=4)\end{array}$ & & & \\
\hline \multirow[t]{2}{*}{ Height } & average & 37 & 32 & 4 & 7 & 162 & P1: 0.5 \\
\hline & stunted & 1 & 1 & 0 & 0 & 2 & P2: 0.43 \\
\hline \multirow[t]{2}{*}{ Weight } & average & 36 & 27 & 4 & 6 & 158 & P1: $0.02 *$ \\
\hline & Under-weight & 2 & 6 & 0 & 1 & 6 & P2: $0.001 * *$ \\
\hline \multirow[t]{2}{*}{ Anemia } & No & 25 & 18 & 4 & 4 & 124 & P1: $0.02 *$ \\
\hline & Yes & 13 & 15 & 0 & 3 & 40 & $\mathrm{P} 2: 0.003 * *$ \\
\hline
\end{tabular}

$\mathrm{P} 2:$ H. nana infected children with non-infected

Table 5: Sensitivity and negative predictive value of different stool examinations to detect E. vermicularis, H. nana, and S. mansoni

\begin{tabular}{|l|c|c|c|c|c|c|c|c|c|}
\hline \multirow{2}{*}{ Variable } & \multicolumn{2}{|c|}{ All helminths } & \multicolumn{2}{c|}{ E. vermicularis $(\mathrm{n}=30)$} & \multicolumn{2}{c|}{ H. nana $(\mathrm{n}=39)$} & \multicolumn{2}{c|}{ S. mansoni $(\mathrm{n}=6)$} & \multirow{2}{*}{ P-value } \\
\cline { 2 - 11 } & $\mathrm{S}$ & $\mathrm{NPV}$ & $\mathrm{S}$ & $\mathrm{NPV}$ & $\mathrm{S}$ & $\mathrm{NPV}$ & $\mathrm{S}$ & $\mathrm{NPV}$ & \\
\hline Direct smear & $37.3 \%$ & $87.4 \%$ & $30 \%$ & $94.6 \%$ & $43.6 \%$ & $94.3 \%$ & $33.3 \%$ & $98.9 \%$ & 0.50 \\
\hline Kato-Katz & $60 \%$ & $91.6 \%$ & $56.7 \%$ & $96.6 \%$ & $64.1 \%$ & $96.3 \%$ & $50 \%$ & $99.2 \%$ & 0.72 \\
\hline McMaster & $81.3 \%$ & $95.9 \%$ & $86.7 \%$ & $98.9 \%$ & $89.7 \%$ & $98.9 \%$ & $0 \%$ & $\mathrm{NA}$ & $<0.001 * * *$ \\
\hline FECM & $77.3 \%$ & $95 \%$ & $80 \%$ & $98.4 \%$ & $76.9 \%$ & $97.6 \%$ & $66.7 \%$ & $99.5 \%$ & 0.77 \\
\hline Mini-FLOTAC FS2 & $90.7 \%$ & $97.9 \%$ & $100 \%$ & $100 \%$ & $97.4 \%$ & $99.7 \%$ & $0 \%$ & NA & $<0.001 * * *$ \\
\hline Mini-FLOTAC FS7 & $94.7 \%$ & $98.8 \%$ & $96.7 \%$ & $99.7 \%$ & $92.3 \%$ & $99.2 \%$ & $100 \%$ & $100 \%$ & 0.60 \\
\hline
\end{tabular}

*Significant $(\mathrm{P}<0.05), * *$ Highly significant $(\mathrm{P}<0.01), * * *$ Very highly significant $(\mathrm{P}<0.001)$

\section{Discussion}

S: Sensitivity, NPV: Negative predictive value
In the present study, the total intestinal helminths were $20.5 \%$ which agreed with Bayoumy et al. (2018) who recorded 22.5\% in Beheira Governorate. Enterobius vermicularis was the most common helminth followed by $H$. nana, and the least one was $S$. mansoni. The high rate of E. vermicularis could be due to its highly infectious nature as the major transmission route is direct person-to-person contact or by autoinfection (Clark et al, 2014). The low S. mansoni rate was due to the success Egyptian National Bilharzial Control Program in Egypt, which reduced the percentage of infection (Fenwick, 2019).

In the present study, mini-FLOTAC ZnSO4 was the most sensitive procedure followed by the mini-FLOTAC $\mathrm{NaCl}$, McMaster, FECM, Kato-Katz, and the least one was direct smear, which agreed with Cringoli (2006). In the present study, mini-FLOTAC ZnSO4 was more se-nsitive than miniFLOTAC $\mathrm{NaCl}$ for $S$. mansoni detection, but mini-FLOTAC $\mathrm{NaCl}$ displayed better detection of $H$. nana and E. vermicularis (Catalano et al, 2019).

Alteration in prevalence of helminnths determined by different methods might be due to changes in $t$ size of studied stool samples, concentration procedure and the flotation solutions used as their specific gravity in eggs flotation.

In the present study, the ROC curve identified the AUC for the copromicroscopic techniques showed significant AUC with miniFLOTAC ZnSO4. Besides, NPV showed that mini-FLOTAC ZnSO4 method was the best technique used. These data agreed with Barda et al. (2013a). Also, when each method was compared with one another or with the combined data, the mini-FLOTAC $\mathrm{NaCl}$ and McMaster methods showed significantly better diagnostic value for both $E$. vermicularis and $H$. nana rather than $S$. mansoni. This agreed with Yimer et al. (2015) and Abd El-Gaffar et al. (2018).

In the present study, for E. vermicularis and $H$. nana, the mini-FLOTAC $\mathrm{NaCl}$ showed highest EPG followed by mini-FLOTAC $\mathrm{ZnSO} 4$, McMaster and the least one was of Kato-Katz. This agreed with Barda et al. (2014) and Adugna et al. (2017). But, with S. mansoni, the mini-FLOTAC ZnSO4 detected more EPG than Kato-Katz. This agreed with Barda et al. (2013b); Barda et al. (2014), and Coulibaly et al. (2016). Ng'etich et al. (2016) reported that helminthiasis was more evident in the hospitalized children samples with heavy infections rather than school children with mild to moderate infections.

In the present study, with E. vermicularis and $H$. nana, mini-FLOTAC $\mathrm{NaCl}$ was more 
dependable than the mini-FLOTAC ZnSO4, McMaster, and Kato-Katz methods, which agreed with Barda et al. (2014), but for $S$. mansoni, mini-FLOTAC $\mathrm{ZnSO} 4$ was better than FECM, or Kato-Katz, and direct smear.

In the present study, the Scotch tape for $E$. vermicularis eggs on perianal region was the best diagnostic technique. This agreed with Shoup (2001) and Kadir and Amin (2011).

In the present study, younger children $(\leq 8$ years) were significantly more infected, due to contagion, outdoor playing, crowded classroom, poor personal hygiene, or sharing personal tools. This agreed with Tigabu et al. (2019). Boys were more infected than girls, but without a significant difference, which agreed with Bayoumy et al. (2016); Liao et al. (2017) due to outdoors activities than females. Besides, children in rural areas were significantly more infected, which agreed with Mohammad et al. (2012) due to environmental pollution. Moreover, risk factors for helminthiasis were the non-washing hands before eating or after defecation, and consumption of unwashed vegetables and fruits. This agreed with Li et al. (2015); Salahi et al. (2019) and Mahmoudvand et al. (2020).

In the present study, there was a significant difference between infected and noninfected school children as to anemia and underweight, while for stunted children not significant, which agreed with Khalil et al. (1991) and Cabada et al. (2016)

In the present study, there was no association between $S$. mansoni and anemia which might be due to the low number of detected cases. But, Butler et al. (2012) found that $S$. mansoni-infected persons were anemic due to inflammation rather than iron deficiency.

The direct smear was simple, cheap and fast, but the McMaster and mini-FLOTAC methods were time consuming followed by Kato-Katz, and then FECM and being more complicated ones (Barda et al, 2014).

\section{Conclusion}

Enterobius vermicularis was the commonest parasite, followed by $H$. nana, but $S$. mansoni was present in some rural areas.
Mini-FLOTAC proved to be a valuable diagnostic technique. Awareness about parasitosis and nutritional status and anemia must be considered by Public Health Authorities.

\section{Acknowledgments}

The authors would like to thank the National Liver Institute, Menoufia University, Egypt for financial support and facilitating this work.

\section{References}

Abd El-Gaffar, MM, Sadek, GS, Oshiba, SF, Esmail, ES, 2018: Evaluation of Feconomics and Mini-FLOTAC as recent stool preparation techniques for the diagnosis of intestinal parasites. J. Egypt Soc. Parasitol. 48, 1:139-46.

Adugna, S, Kebede, T, Mekonnen, Z, Degarege, A, Liang, S, et al, 2017: Diagnostic performance of Mini Parasep ${ }^{\circledR}$ solvent-free faecal parasite concentrator relative to Kato-Katz and McMaster for the diagnosis of intestinal parasitic infections. Trans. Roy. Soc. Trop. Med. 111: 572-8.

Barda, B, Rinaldi, L, Ianniello, D, Zepherine, H, Salvo, F, et al, 2013a: Mini-FLOTAC, an innovative direct diagnostic technique for intestinal parasitic infections: Experience from the fie1d. PLoS Negl. Trop. Dis. 7:e2344.

Barda, B, Zepharine, H, Rinaldi, L, Cringoli, G, Burioni, R, et al, 2013b: Mini-FLOTAC and Kato-Katz: Helminth eggs watching on the shore of Lake Victoria. Parasit. Vect. 6:1-6.

Barda, B, Cajal, P, Villagran, E, Cimino, R, Juarez, M, et al, 2014a: Mini-FLOTAC, KatoKatz, and McMaster: Three methods, one goal, highlights from north Argentina. Parasit. Vect. 7 $: 1-7$.

Barda, B, Ianniello, D, Zepheryne, H, Rinaldi, L, Cringoli, G, et al, 2014b: Parasitic infections on the shore of Lake Victoria (East Africa) detected by Mini-FLOTAC and standard techniques. Acta Trop. 137:140-6.

Bayoumy, AS, Ibrahim, WF, Abou El-Nour, BM, Said, AA, 2016: The parasitic profile among school children in El-Wadi El-Gadded Governorate, Egypt. J. Egypt Soc. Parasitol. 46, 3: 605-12.

Bayoumy, AS, Abd El-Raheem, MA, Abo Hashim, AH, 2018: Parasitic profile among primary school children in a rural area at Beheira Governorate, Egypt. Egypt. J. Hosp. Med. 70:20429.

Butler, SE, Muok, EM, Montogomery, SP, 
Odhiambo, K, Mwinzi, PM, et al, 2012: Mechanism of anemia in Schistosoma mansoni-infected school children in western Kenya. Am. J. Trop. Med. Hyg. 87:862-7.

Cabada, MM, Morales, MI, Lopez, M, Reynolds, ST, Vilchez, EC, et al, 2016: Hymenolepis nana impact among children in the highlands of Cusco, Peru: An emerging neglected parasite infection. Am. J. Trop. Hyg. 95:1031-6.

Catalano,S, Symeou, A, Marsh, KJ, Borlase, A, Leger, E, et al, 2019: Mini-FLOTAC as an alternative, non-invasive diagnostic tool for $\mathrm{Sch}$ istosoma mansoni and other trematode infections in wildlife reservoirs. Parasit.Vect. 12, Art. No. 439.

Clark, CG, Röser, D, Stensvold, CR, 2014: Transmission of Dientamoeba fragilis: Pinworm or cysts?Trends Parasitol. 30, 3:136-40

Coulibaly, JT, Ouattaraa, M, Beckerc, SL, Lo, NC, Keiser, J, et al, 2016: Comparison of sensitivity \& fecal egg counts of Mini-FLOTAC using fixed stool samples and Kato-Katz technique for the diagnosis of Schistosoma mansoni and soil-transmitted helminths. Acta Trop. 164: 107-16.

Cringoli, G, 2006: FLOTAC, a novel apparatus for a multivalent faecal egg count technique. Parasitol. 48:381-4.

Fenwick, A, 2019: Egypt's schistosomiasis control programme in the 1980s prepared the ground for the global elimination of schistosomiasis by 2030.Trans. R. Soc. Trop. Med. Hyg. 113, 1:1-3.

Gibson, RS, 2005: Principle of nutrition assessment. Second edition. Oxford University Press, USA.

Hegazy, AM, Uounis, NT, Aminou, HA, Badr, AM, 2014: Prevalence of intestinal parasites and its impact on nutritional status among preschool children living in Damanhur City, El-Behera Governorate, Egypt. J. Egypt Soc. Parasitol. 44: 517-524.

Kadir MA, Amin, OM, 2011: Prevalence of enterobiasis (Enterobius vermicularis) and its impact on children in Kalar Town/Sulaimania, Iraq. Tikrit Med. J. 17:67-77.

Katz, N, Chaves, A, Pellegrino, J, 1972: A simple device for quantitative stool thick-smear technique in schistosomiasis mansoni. Rev. Inst. Med. Trop. Sao Paulo 14:397-400.

Khalil, HM, El Shimi, S, Sarwat, MA, Fawzy, AF, El Sorougy, AO, 1991: Recent study of Hymenolepis nana infection in Egyptian child- ren. J. Egypt Soc. Parasitol. 21, 2:293-300.

Kurt, O, Akyar, I, Gorgun, S, Kocagoz, T, Ozbilgin, A, 2012: Feconomics: a simple, novel, and fast technique for stool concentration in parasitology laboratory. Kafkas Univ. Vet. Fak. Derg. 18:161-5.

Levecke, B, Behnke, JM, Ajjampur, SR, Albonico, M, Ame, SM, et al, 2011: A comparison of the sensitivity and faecal egg counts of the McMaster egg counting and Kato-Katz thick smear methods for soil-transmitted helminths. PLoS Negl. Trop. Dis. 5:e1201.

Li, HM, Zhou, CH, Li, ZS, Deng, ZH, Ruan, CW, et al, 2015: Risk factors for Enterobius vermicularis infection in children in Gaozhou, Guangdong, China. Infect. Dis. Poverty 4:28-35. Liao, CW, Chiu, KC, Chiang, IC, Cheng, PC, Chuang, TW, et al, 2017: Prevalence and risk factors for intestinal parasitic infection in schoolchildren in Battambang, Cambodia. Am. J. Trop. Med. Hyg. 96:583-8.

Lim, MD, Brooker, SJ, Belizario, VJ, GayAndrieu, F, Gilleard, J, et al, 2018: Diagnostic tools for soil-transmitted helminths control and elimination programs: A pathway for diagnostic product development. PLoS Negl. Trop. Dis. 12: e00006213.

Mahmoudavand, H, Badparva, E, Khalaf, A K, Niazi, M, Khatami, M, et al, 2020: Prevalence and associated risk factors of intestinal helminthic infections in children from Lorestan province, Western Iran. Parasite Epidemiol. Control 9:e00136.

Mohammad, KA, Mohammad, AA, Abu ElNour, MF, Saad, MY, Timsah, AG, 2012: The prevalence and associated risk factors of intestinal parasitic infections among school children living in rural and urban communities in Damietta governorate, Egypt. Acad. Arena 4:90-97.

Ng'etich, AI, Rawago, FO, Jura, WO, Mwinzi, PN, Won, KY, et al, 2016: A cross-sectional study on schistosomiasis and soil-transmitted helminths in Mbita district, western Kenya using different copromicroscopic techniques. Parasit.

Vect. 9:1-9.

Onis, MD, Onyango, AW, Borghi, E, Siyam, A, Nishida, C, et al, 2007: Development of a WHO growth reference for school-aged children and adolescents. Bull. WHO 85:660-7.

Salahi, K, Javadi, A, Saraei, M, 2019: Prevalence of intestinal parasites and risk factors with emphasis on Enterobius vermicularis in children of daycares and preparatory schools of the city 
of Khodabandeh, Northwestern Iran. Indian J.

Med. Spec. 10:89-94.

Shoup, B, 2001: Diagnosis and management of pinworm infection. Prim. Care Update Ob. Gyns. 8: 240-3.

Tigabu, A, Taye, S, Aynalem, M, Adane, K, 2019: Prevalence and associated risk factors of intestinal parasitic infections among patients attending Shahura Health Center, Northwest Ethiopia. BMC Res. 12:333-41.

WHO, 1991: Basic Laboratory Methods in Me- dical Parasitology. Geneva, Switzerland.

WHO, 1994: Bench aids for the diagnosis of intestinal parasitic infections. WHO, Geneva, Switzerland.

WHO, 2001: Iron deficiency anemia. Assessment, prevention, and control. A guide for programme managers. Geneva, Switzerland.

Yimer, M, Hailu, T, Mulu, W, Abera, B, 2015: Evaluation performance of diagnostic methods of intestinal parasitosis in school-age children in Ethiopia. BMC Res. 8:1-5.

\section{Explanation of figures}

Fig.1 (a-f): H. nana egg detected microscopically at 10x by direct smear (1a), Kato-Katz (1b), FECM (1c), McMaster (1d), mini-FLOTAC FS2 (1e), and mini-FLOTAC FS7 (1f).

Fig.2 (a-f): E. vermicularis egg detected microscopically at $10 \mathrm{x}$ by direct smear (2a), Kato-Katz (2b), FECM (2c), McMaster (2d), miniFLOTAC FS2 (2e), and mini-FLOTAC FS7 (2f).

Fig. 3 (a-d): S. mansoni egg detected microscopically at 10x by direct smear (3a), Kato-Katz (3b), FECM (3c), and mini-FLOTAC FS7 (3d). Fig.4 (a, b, \& c): E. vermicularis, H. nana, \& S. mansoni eggs detected microscopically at 40x by Kato-Katz, mini-FLOTAC FS2, \& FECM respectively.

Gr.1: Receiving operation characteristics (ROC) curve analysis of different methods in detection of helminths.

Graph 2: Comparison of eggs per gram (EPG) of feces (arithmetic mean and standard error) for quantitative techniques.

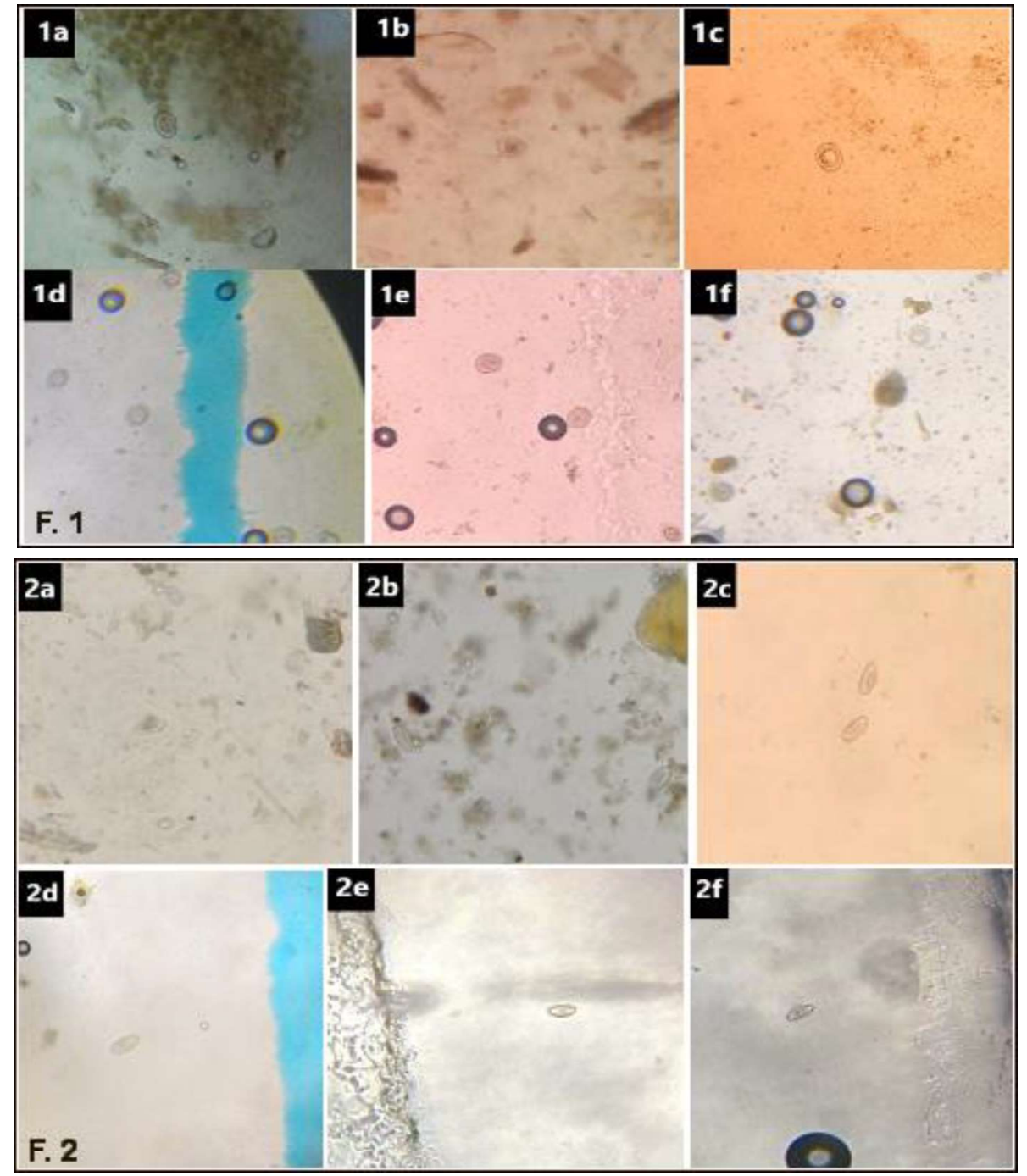



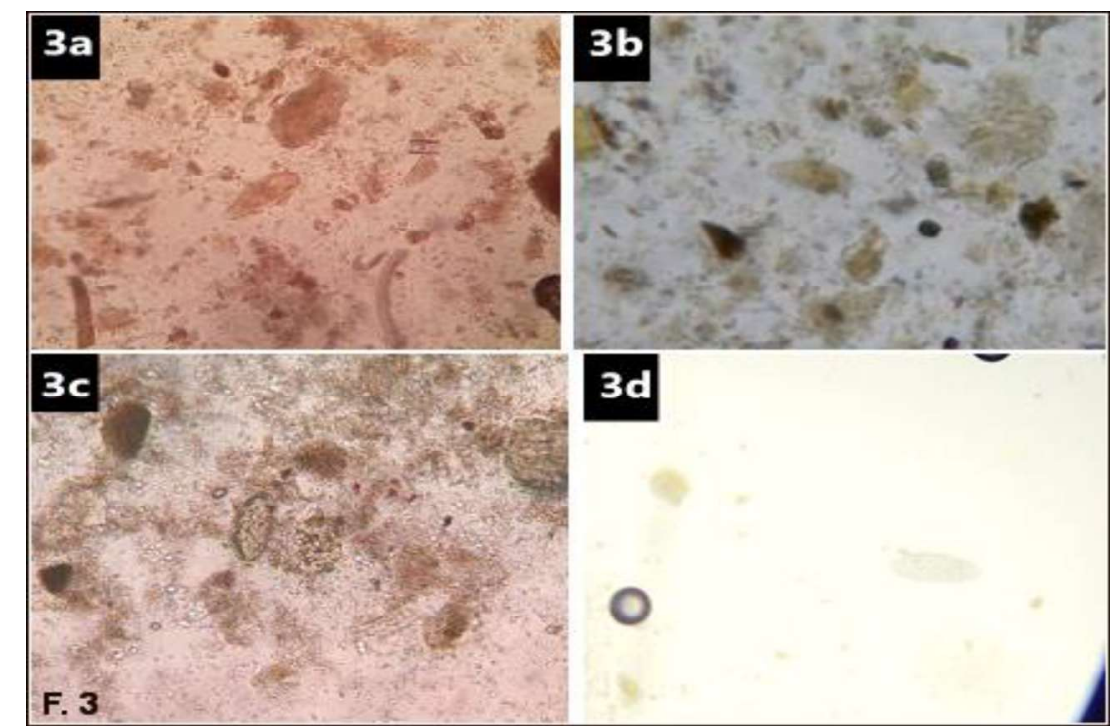

$3 d$
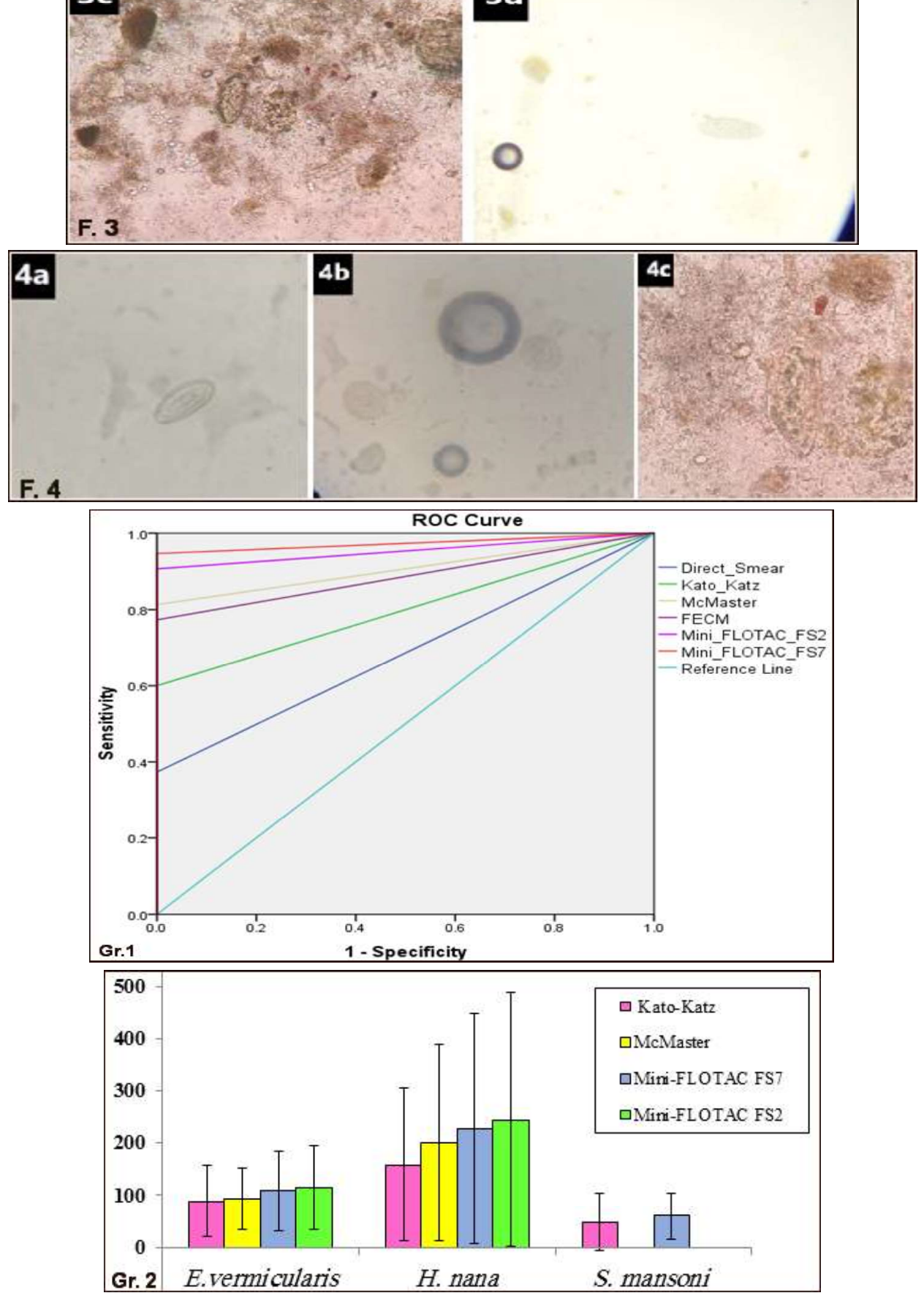